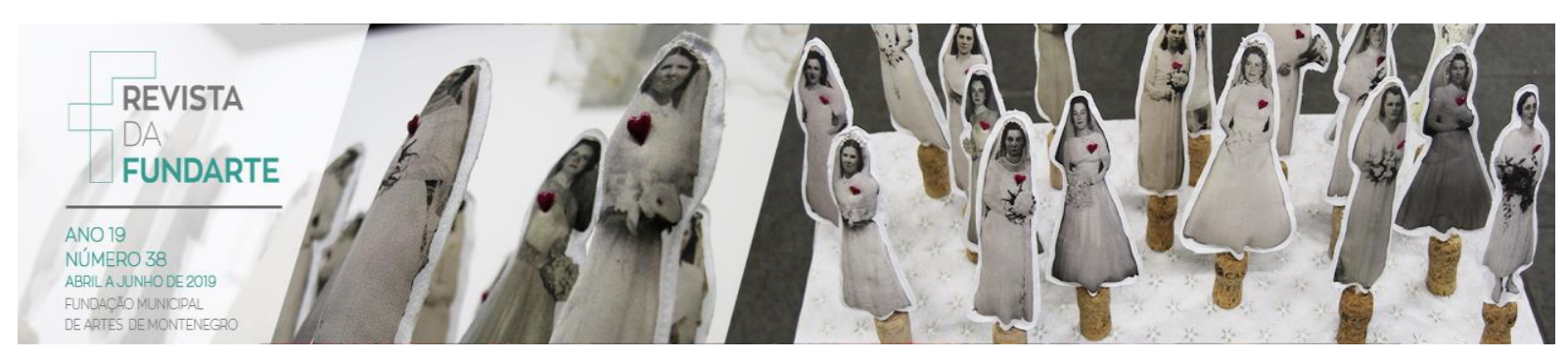

\title{
A PESQUISA PARTICIPANTE E O ERRO NA ENCENAÇÃO DE AGRESTE (MALVA-ROSA)
}

Railson Gomes Almeida ${ }^{1}$

\begin{abstract}
Resumo: A pesquisa em questão visa oferecer um estudo acerca do processo de encenação do espetáculo Agreste (Malva-Rosa), desenvolvido na cidade de João Pessoa - PB no ano de 2017. A observação do espetáculo terá como objetivo estabelecer relações com a pesquisa participante, obtido por meio de uma viagem do elenco no meio do processo; e com a ideia de erro (desvio do padrão) que permeou os ensaios, gerando instabilidade ao coletivo. Ao final do estudo, pretende-se refletir acerca dessas convergências entre a encenação de Agreste (Malva-Rosa) com as premissas de pesquisa participante e erro.

Palavras-Chave: Agreste (Malva-Rosa), Pesquisa Participante, Processo de encenação.

\section{THE RESEARCH PARTICIPANT AND THE ERROR IN THE STAGING OF AGRESTE (HOLLYHOCK)}

\begin{abstract}
The research in question aims to offer a study about the process of staging the Agreste (Malva-Rosa), developed in the city of João Pessoa - PB in the year 2017. The observation of the show will aim to establish relations with the participant research obtained by middle of a cast trip in the middle of the process; and with the idea of error (standard deviation) that permeated the trials, generating instability to the collective. At the end of the study, we intend to reflect on these convergences between the staging of Agreste (Malva-Rosa) with the premises of participant research and error.
\end{abstract}

Key-words: Agreste (Malva-Rosa), Participant Research, Process of staging.

\section{APONTAMENTOS PRÉVIOS}

Eu não confio na pesquisa solitária, confio na pesquisa solidária. (PIAGET apud BRANDÃO \& STRECK. In: BRANDÃO \& STRECK, 2006, Pag. 12).

Essa escrita parte do interesse de relatar o processo de criação do espetáculo Agreste (Malva-Rosa), sob o olhar de dois elementos metodológicos que podem ser visualizados dentro da peça: A pesquisa participante, vivenciada por meio de uma viagem para uma região semelhante à descrita do texto base; e a ideia de erro como elemento que desestabiliza e ao mesmo tempo ajuda e compõe a montagem colaborativa do espetáculo em questão.

\footnotetext{
${ }^{1}$ Mestrando em Artes Cênicas da UFRN
}

ALMEIDA, Railson Gomes. A pesquisa participante e o erro na encenação de agreste (Malva-Rosa). Revista da FUNDARTE, Montenegro, p.79-94, ano 19, ํo 38, abril/junho de 2019. Disponível em: http://.seer.fundarte.rs.gov.br/index.php/RevistadaFundarte/index> 28 de junho de 2019. 


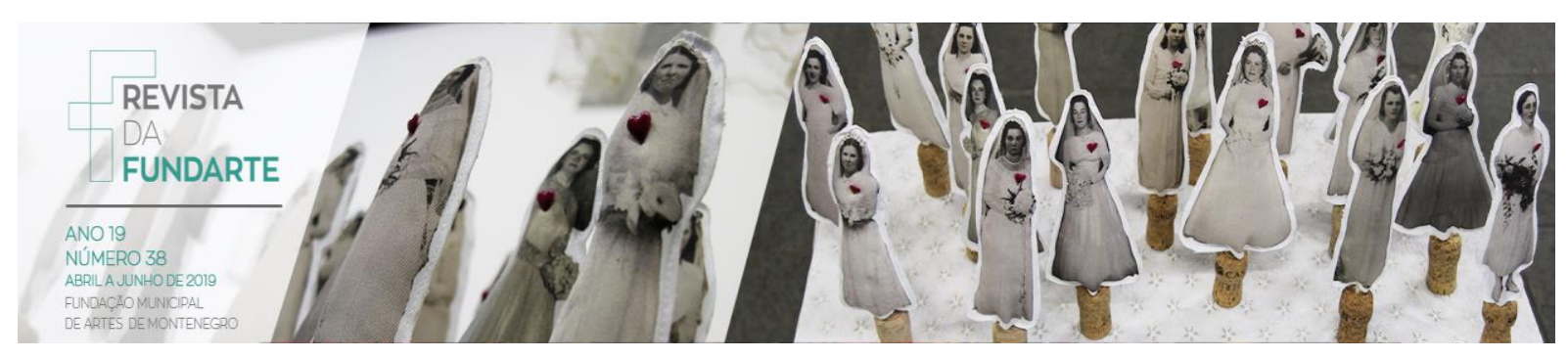

Além do relato do processo de criação do espetáculo que foi vivenciada pelo autor da escrita (que se coloca em terceira pessoa), serão inseridas leituras de outros escritos. A priori, $O$ que é pesquisa participante? de Luis R. Gabarrón e Libertad Hernandez Landa; e A "escrita dos erros": sobre os possíveis modos de registro na pesquisa em artes da cena de Moacir Romanini Junior e Mateo Bonfitto.

A escrita poderá ser visualizada em cinco partes: a primeira dará conta de relatar os principais acontecimentos do processo de encenação do espetáculo Agreste (Malva-Rosa) com influência do texto Sistematização das experiências: algumas apreciações de Oscar Jara Holliday; no segundo momento, pretende-se falar acerca da pesquisa participante, procurando uma síntese do assunto; na terceira parte, a escrita focará na ideia do erro e de como esse ato mesmo tendo estigma negativo por parte da sociedade, consegue gerar bons frutos; o quarto momento focará na relação entre o espetáculo e as premissas metodológicas explicitadas, apontando assim relações convergentes entre a pesquisa participante, o erro dentro do processo e do espetáculo em si; e finalizando a escrita, algumas considerações finais externando algumas reflexões acerca dessa pesquisa.

\section{O PROCESSO DE ENCENAÇÃO DE AGRESTE (MALVA-ROSA)}

As experiências são sempre experiências vitais, carregadas de enorme riqueza; e mais, cada experiência constitui um processo inédito e irrepetível [...]; por isso é fundamental extrair seus ensinamentos e por isso é também importante comunica-los, compartilha-los. (HOLLIDAY. In: BRANDÃO \& STRECK, 200.6, p. 229).

Antes de iniciar a escrita do relato em questão, é importante frisar que ela se afeta do texto Sistematização das experiências: algumas apreciações, em que é discorrido sobre as experiências e suas formas de sistematização e desenvolvimento num trabalho de pesquisa. No texto, o autor entende que "a experiência [...] é constituída por ações [...] e percepções e é constituída também por sensações, emoções e interpretações das pessoas que vivem essas experiências

ALMEIDA, Railson Gomes. A pesquisa participante e o erro na encenação de agreste (Malva-Rosa). Revista da FUNDARTE, Montenegro, p.79-94, ano 19, no 38, abril/junho de 2019. Disponível em: http://.seer.fundarte.rs.gov.br/index.php/RevistadaFundarte/index> 28 de junho de 2019. 


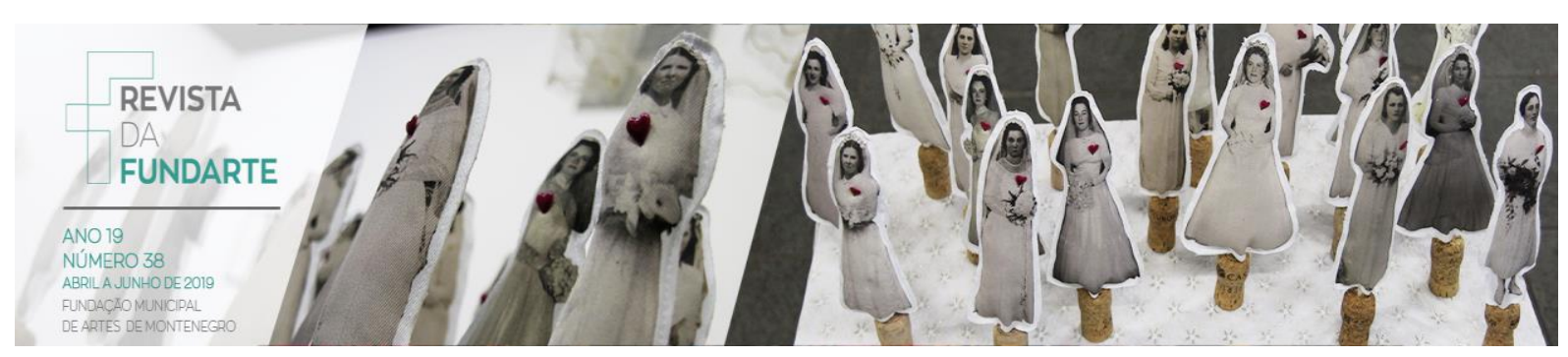

[...] não há somente fatos e coisas [...] há pessoas que sentem, vivem e que fazem coisas" (HOLLIDAY. In: BRANDÃO \& STRECK, 2006, Pag. 228); assume-se assim, que se trata de uma escrita contaminada pela experiência do autor que vivenciou todo o processo de encenação em questão.

No ano de 2017, na cidade de João pessoa - PB inicia-se o processo de montagem cênica do texto Agreste (Malva-Rosa) ${ }^{2}$ do escritor pernambucano radicado na cidade de São Paulo, Newton Moreno. Inicialmente, o processo foi requisito da disciplina de Estágio Supervisionado do Bacharelado em Teatro da Universidade Federal da Paraíba. O resultado gerado foi um espetáculo teatral de nome homônimo ao texto e foi apresentado durante todo ano de 2017 em diversas situações.

O processo teve inicio no mês de fevereiro quando os alunos matriculados na disciplina de Estágio Supervisionado do Bacharelado em Teatro da UFPB se encontram nas dependências da universidade, juntamente com professor e coordenador/diretor do processo Everaldo Vasconcelos, docente do Departamento de Artes Cênicas da instituição.

Os encontros do grupo foram diários e se davam entre as 14:00 e 17:30, sempre na Sala 06 do Prédio conhecido por Abacatão (oficialmente DAC Departamento de Artes Cênicas), no próprio Campus central da Universidade. Inicialmente, a montagem contava com onze alunos, no entanto as pessoas foram abandonando o processo, restando assim um elenco de quatro atores: Maria Bethânia; João Fernandes; Jofran di Carvalho e Railson Almeida, que juntos terminaram o processo de montagem em questão.

2 SINOPSE DO TEXTO: A história de Agreste (Malva-rosa) se passa numa cidade do interior. Começa com um flerte entre um casal de lavradores, um de cada lado de uma cerca, através da qual eles descobrem o amor. Mas eles percebem que há algo neste sentimento "que não deveria acontecer". Apesar disso, um dia, rompem a cerca e fogem, sertão adentro, para viverem juntos, num casebre. Porém, pressentem que algo de perigoso paira sobre eles. A esposa compreende o porquê, depois de 22 anos, quando perde subitamente o esposo. Durante o velório, as idosas carpideiras, ao prepararem o morto, descobrem que o "marido" é uma mulher. Após esta reviravolta, sucedem-se levantes de repulsa e homofobia. Machucada pela perda, sem entender a dimensão de seus atos, a esposa acaba sendo vítima do horror e da intolerância do povo.

FONTE: <http://www.funarte.gov.br/teatro/funarte-apresenta-agreste-malvarosa-em-cinco-cidades-do$\mathrm{rj} />$ Acesso em: 26 jun 2018 às 14:10

ALMEIDA, Railson Gomes. A pesquisa participante e o erro na encenação de agreste (Malva-Rosa). Revista da FUNDARTE, Montenegro, p.79-94, ano 19, no 38, abril/junho de 2019. Disponível em: http://.seer.fundarte.rs.gov.br/index.php/RevistadaFundarte/index> 28 de junho de 2019. 


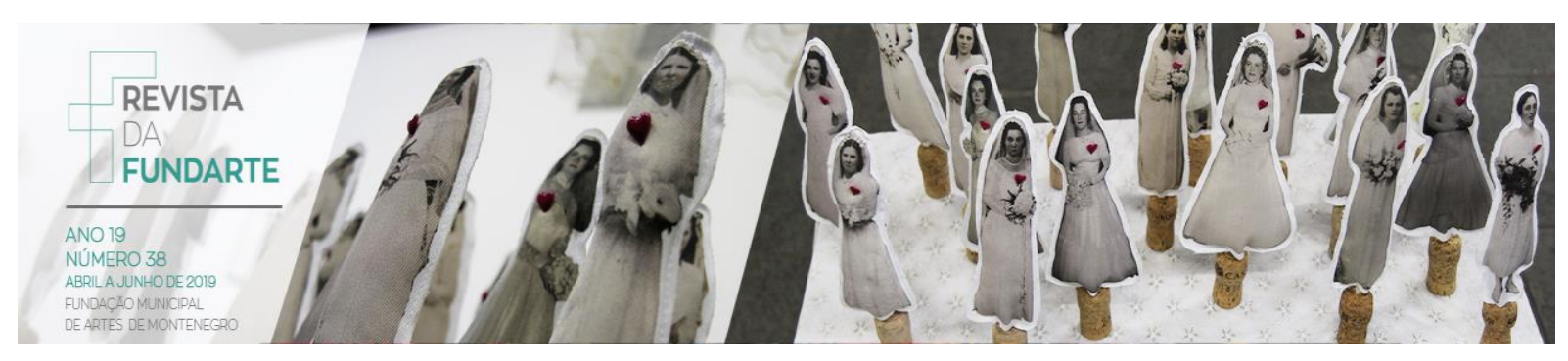

Muitos textos foram lidos, até que Agreste (Malva-Rosa) de Newton Moreno fosse o escolhido por unanimidade pelos envolvidos. Como dito, o processo se deu numa sala específica e os encontros eram diários. A direção era colaborativa, mas sempre mediada e observada pelo diretor, os atores propunham as cenas por meio de improvisos e a direção partia das proposições para tomar a decisão final.

A sala 06 nunca era trancada e por muitas vezes algumas pessoas adentravam no espaço, acompanhavam os ensaios, falavam suas impressões e davam algumas sugestões, que eram inseridas no processo na medida do possível. Depois, esses mesmos convidados passaram a doar elementos cenográficos e figurinos, que também foram incorporados no espetáculo. Sendo assim, o processo foi duplamente cooperativo, primeiro entre direção e atores; e segundamente entre os envolvidos no processo e público externo.

O processo em si não foi algo linear e contínuo, houve alguns percalços e fatos que alteraram o andamento dos ensaios, como por exemplo, uma crise da saúde de um dos membros que o obrigou a se afastar por duas semanas dos ensaios. Aconteceu também uma viagem para o interior da Paraíba, que será relatado mais a frente que também veio a modificar o espetáculo, entre outros contratempos.

Uma de nossas grandes características foi a utilização da sala não apenas como sala de ensaios, mas também como um lugar de "morada" dos atores, da direção e das pessoas externas que acompanhavam o processo continuamente. De forma que a sala também servia como depósito do material cênico e como cozinha do grupo, quando se adquiriu de um fogão elétrico, no qual os presentes faziam refeições no final do ensaio. A aproximação com esse espaço tornou-se tão forte que aquela pequena sala abandonada foi transformada no palco de todas as apresentações da primeira temporada.

A estreia e a temporada se deram no mês de junho do mesmo ano dentro dessa sala agora chamada de Sala Preta ou Teatro Depósito. Essa primeira série contou com dez apresentações, todas no mesmo espaço. Após a temporada, o grupo não encerra com as apresentações, mas adentra novamente em processo

ALMEIDA, Railson Gomes. A pesquisa participante e o erro na encenação de agreste (Malva-Rosa). Revista da FUNDARTE, Montenegro, p.79-94, ano 19, no 38, abril/junho de 2019. Disponível em: http://.seer.fundarte.rs.gov.br/index.php/RevistadaFundarte/index> 28 de junho de 2019. 


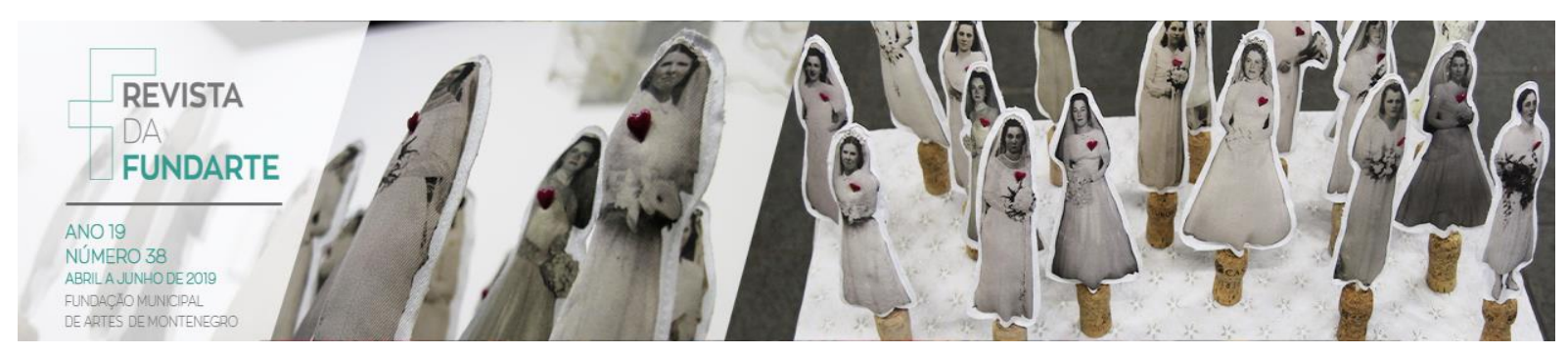

para retomar e remodelar a encenação, pois um dos atores precisou afastar-se sendo preciso substituí-lo; no mês de setembro do mesmo ano Agreste é reestreia com a presença da atriz Fabíola Ataíde, sendo feita apresentações em diferentes ambientes acadêmicos. O grupo se batiza e passa a se chamar de Mulungu e busca a autorização oficial de Newton Moreno (autor do texto) para apresenta-lo em âmbito profissional, tal investida não obteve resposta acerca dos direitos autorais, então o coletivo decide finalizar o espetáculo ainda no final do mês de novembro do ano de 2017.

\section{APONTAMENTOS SOBRE A PESQUISA PARTICIPANTE}

Fazer ciência popular [...] "é criar uma ciência em um duplo sentido. Primeiro, porque está comprometida com a causa popular; segundo, porque pensa a partir da lógica do povo, buscando construir sua verdade com base nas experiências políticas e na maneira em que percebe sua realidade" .(BRANDÃO ${ }^{3}, 1987$, p. 39 apud GABARRÓN \& LANDA. In: BRANDÃO \& STRECK, 2006, p. 13-114).

A pesquisa participante emerge por volta dos anos 1960 e a América Latina 4 teve papel fundamental no desenvolvimento da modalidade. A grande problemática que esse método vem sanar é da dificuldade de algumas pesquisas, a priori, das ciências humanas (principalmente as ciências sociais) de fazer seus estudos com métodos científicos positivistas e funcionalistas, como se fazia na maior parte das

\footnotetext{
3 Trata-se da seguinte referência: BRANDÃO, Carlos Rodrigues; e BORDA, Orlando Fals. Pesquisa participante. $2^{\mathrm{a}}$ Ed., Montivideo: Edições da Banda Oriental. 1987, 73 p.

${ }^{4} \mathrm{O}$ grande fator levantado, é que os países da América latina estariam passando por um processo de "crise estrutural, social e política" (Pag. 99). E estariam assim, questionando as estruturas metodológicas vigentes, procurando métodos que se encaixassem nesta realidade (PINTO, 1988, pag. 42 apud GABARRÓN \& LANDA. In: BRANDÃO \& STRECK, 2006, pag. 101). Assim, se inicia "um amplo movimento latino-americano de reação e recuso ao predomínio esterilizante do positivismo empirista na prática das ciências sociais". Havendo então uma série de estudos nessa região entre os anos 1960 e 1970: "Trata-se da teoria da dependência, de Cardoso, Faletto e outros; a efervescência popular em vários países que culmina com a revolução cubana e o histórico de 1968; a sociologia da exploração de Pablo González Casanova; a vida e a morte do subversivo Camilo Torres; e de Che Guevara; também se destacam no mesmo período a Educação Popular libertadora de Paulo Freire, a revolução sandinista na Nicarágua" (GABARRÓN \& LANDA. In: BRANDÃO \& STRECK, 2006, pag.101).
}

ALMEIDA, Railson Gomes. A pesquisa participante e o erro na encenação de agreste (Malva-Rosa). Revista da FUNDARTE, Montenegro, p.79-94, ano 19, no 38, abril/junho de 2019. Disponível em: http://.seer.fundarte.rs.gov.br/index.php/RevistadaFundarte/index> 28 de junho de 2019. 


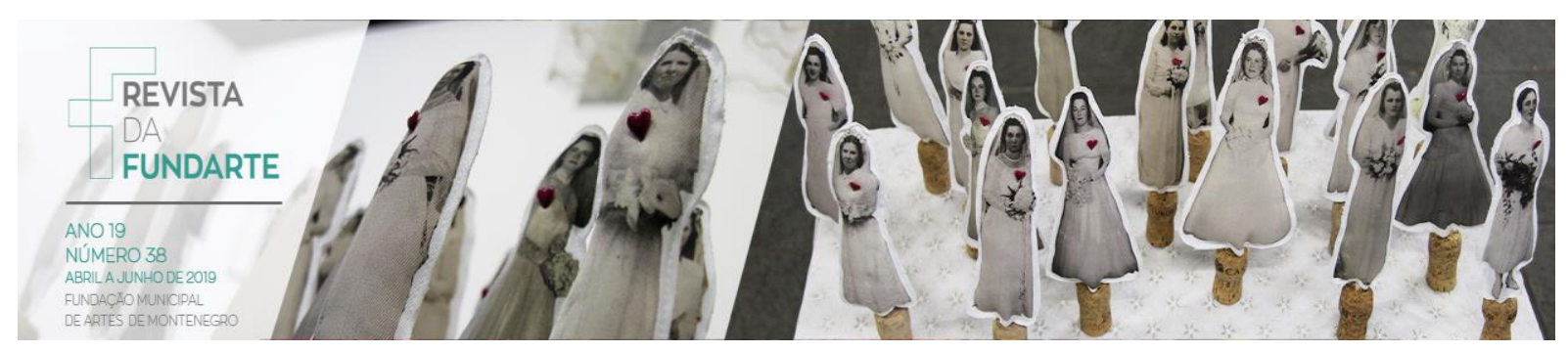

"ciências" exatas e biológicas. Como seria possível, por exemplo, analisar uma determinada região ou uma determinada comunidade em uma sala de estudo ou num laboratório?

Era então preciso uma abordagem diferente de objetos de estudo que tratassem das relações humanas, sociais e afins. Para entender determinados contextos e realidades é preciso uma apreciação daquela sociedade ou individuo em estado puro, considerar as experiências e o saber popular dentro do conhecimento cientifico. Logo, a pesquisa participante surge tentando resolver algumas questões como está:

Seu compromisso [...] é colocar o conhecimento a serviço dos interesses populares para a transformação da sociedade em geral [...] representando uma resposta ao problema de conhecer e atuar numa realidade concreta para resolver problemas específicos (GABARRÓN \& LANDA. In: BRANDÃO \& STRECK, 2006, Pag. 109).

De modo geral, a Pesquisa Participante tem principalmente dois vieses. A primeira é a observação e o ato de conhecer e entender a realidade que se pretende estudar, logo, não basta apenas o estudo bibliográfico e o saber cientifico, é preciso visitar, interagir e se debruçar sobre outros tipos de conhecimentos e os variados saberes populares e entender as relações históricas que levaram a realidade visualizada e sua presença/participação em relação a outros processos distintos, pois,

[...] se, ao estudar os processos, os fenômenos ou os sistemas sociais, não for considerada sua dimensão histórica e as operações ideológicas subjacentes, perder-se-á o caráter essencial, sua natureza.(GABARRÓN \& LANDA. In: BRANDÃO \& STRECK, 2006, Pag. 97).

O segundo viés está no caráter de transformação da realidade observada. Sendo assim, não cabe apenas observar, coletar dados e analisa-los, é preciso também procurar intervir e buscar sanar os problemas encontrados. Como Gabarrón e Landa colocam, é preciso Conhecer transformando.

ALMEIDA, Railson Gomes. A pesquisa participante e o erro na encenação de agreste (Malva-Rosa). Revista da FUNDARTE, Montenegro, p.79-94, ano 19, oㅡ 38, abril/junho de 2019. Disponível em: http://.seer.fundarte.rs.gov.br/index.php/RevistadaFundarte/index> 28 de junho de 2019. 


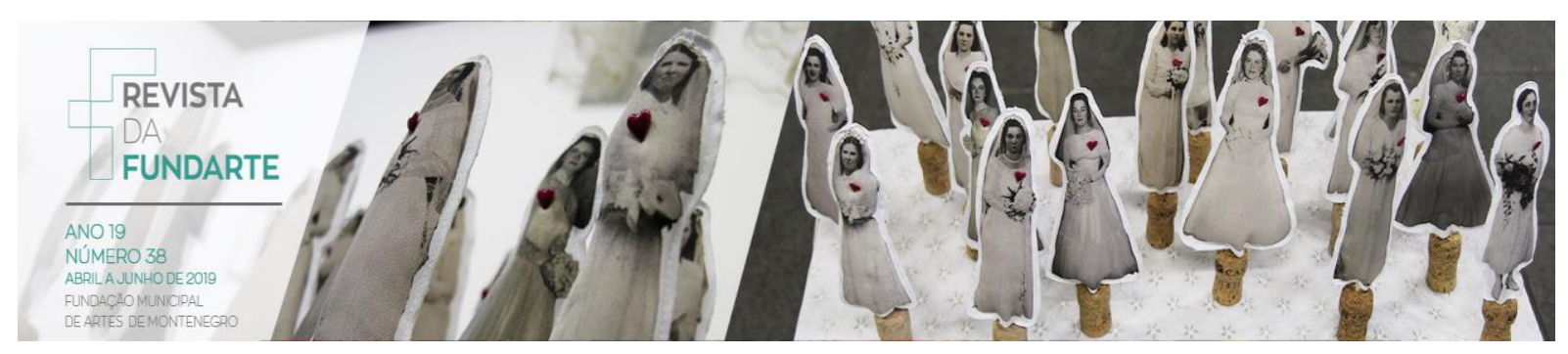

Uma pesquisa participante pode ser dividida, a priori, em três grandes modalidades. O primeiro seria a ação transformadora, estando este relacionado os problemas encontrados e a busca por soluções que venham sanar ou auxiliar o coletivo. A segunda seria a própria produção de conhecimento, que seria o ato de conhecer determinados saberes e contextos e confrontá-los com a produção cientifica, podendo um agregar o outro. A terceira categoria é a própria participação, estando ligado ao nível de engajamento e intimidade do pesquisador participante com o objeto de estudo e quanto isso afeta a pesquisa.

Assim, esse método não possui um determinado roteiro a ser seguido pelos pesquisadores, pois cada estudo tem sua abordagem especifica deixando a cargo do investigador a definição de sua rota. No entanto, a pesquisadora Marcela Gajardo, irá citar uma série de premissas acerca das necessidades e funções da pesquisa participante:

-O ponto de partida é a realidade concreta dos grupos com quem se trabalha;

-a luta por estabelecer relações horizontais e antiautoritárias;

-a prioridade dos mecanismos democráticos na divisão de trabalho;

-o impulso dos processos de aprendizagem coletiva através de práticas grupais;

-o reconhecimento das implicações políticas e ideológicas subjacentes a qualquer prática social, seja de pesquisa ou de educação;

- o estímulo à mobilização de grupos e organizações para a transformação da realidade social, ou para ações em benefício da própria comunidade, e

-a ênfase á produção e comunicação de conhecimento.

(GAJARDO5 ${ }^{5}$, 1983, pag. 73-78 apud GABARRÓN \& LANDA. In: BRANDÃO \& STRECK, 2006, Pag. 112).

A conceituação ou definição da pesquisa participante não é algo tão simples de propor, no entanto, Gabarrón e Landa se sustentando em outros autores, talvez

\footnotetext{
5 Trata-se da seguinte referência: GAJARDO, Marcela. Investigación participativa: propuestas y proyectos. Revista Latinoamaericana de Estúdios Educativos., vol. 13, n.1, 1983, p.49-83. Centro de Estúdios AC. México DF.
}

ALMEIDA, Railson Gomes. A pesquisa participante e o erro na encenação de agreste (Malva-Rosa). Revista da FUNDARTE, Montenegro, p.79-94, ano 19, oㅡ 38, abril/junho de 2019. Disponível em: http://.seer.fundarte.rs.gov.br/index.php/RevistadaFundarte/index $>28$ de junho de 2019. 


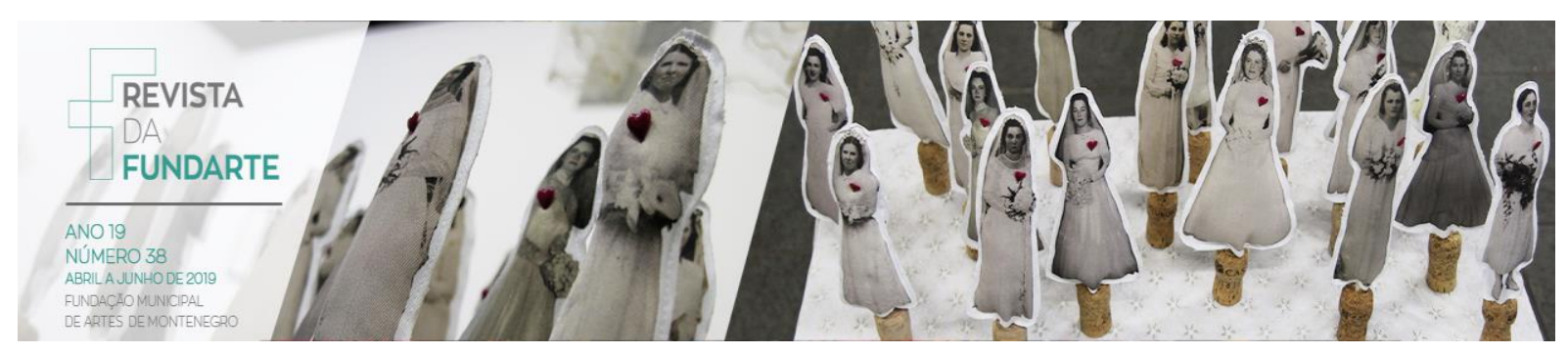

consigam propor uma síntese ou um conceito do que viria a ser esse método de pesquisa:

A pesquisa participante [...] se define [...] como uma proposta metodológica inserida em uma estratégia de ação definida, que envolve seus beneficiários na produção de conhecimento. [...] É um processo que combina pesquisa científica e a ação política para transformar a realidade social e econômica para construir o poder popular em favor dos explorados $\left(\right.$ BORDA $^{6}$, 1986, P. 126; GAJARDO $^{7}, 1986$, P.8). Busca compreender a situação concreta e objetiva da dominação de classe e a percepção dela têm as pessoas dominadas para, junto com elas, produzir os conhecimentos necessários dirigidos a definir ações de transformação da realidade; esta compreendida como uma totalidade (PINTO ${ }^{8}, 1988$, P.43). (GABARRON \& LANDA. In: BRANDÃO \& STRECK, 2006, Pag. 113-114).

\section{APONTAMENTOS SOBRE O ERRO}

A palavra erro deriva de errar e segundo o dicionário de língua portuguesa Mini Aurélio, elas têm o seguinte significado:

er.ro (Dev. de errar] 1. Ato ou afeito de errar. 2. Juízo falso. 3. Incorreção, inexatidão. 4. Desvio do bom caminho. 5. Fís. Qualquer medida da flutuação ou da incerteza associada a uma medição.

er.rar [Lat. Errare] 1. Cometer erro, enganar-se. 2. Não acertar. 3.Errar. 4. Andar a esmo; vagar. 5. Percorrer. 6. Cometer erros(s); falhar. 7. Vagabundear. (FERREIRA, 2010, p. 299).

De modo geral, a sociedade tende a recriminar o erro em diferentes lugares, no âmbito familiar, no ambiente da escola, na universidade, no trabalho, na vida em si. O ser humano moderno tem no errar uma grande mácula que grita por ser

\footnotetext{
6 Trata-se da seguinte referência: BORDA, Orlando Fals. Conocimiento y poder popular: lecciones com campesinos de Nicarágua, México, Colômbia. Bogotá: Século XXI, 1986, p.117

7 Trata-se da seguinte referência: GAJARDO, Marcela. Pesquisa participante na América Latina. São Paulo: Editora Brasiliense, 1986, 94 p.

8 Trata-se da seguinte referência: PINTO, João Bosco. La investigación-acción como práctica social. Cadernos de Sociologia, 6, janeiro-abril de 1988, p.42-54. Escola de Sociologia da Universidade Centroamericana. Manágua, Nicarágua.
}

ALMEIDA, Railson Gomes. A pesquisa participante e o erro na encenação de agreste (Malva-Rosa). Revista da FUNDARTE, Montenegro, p.79-94, ano 19, ํㅡ 38, abril/junho de 2019. Disponível em: http://.seer.fundarte.rs.gov.br/index.php/RevistadaFundarte/index> 28 de junho de 2019. 


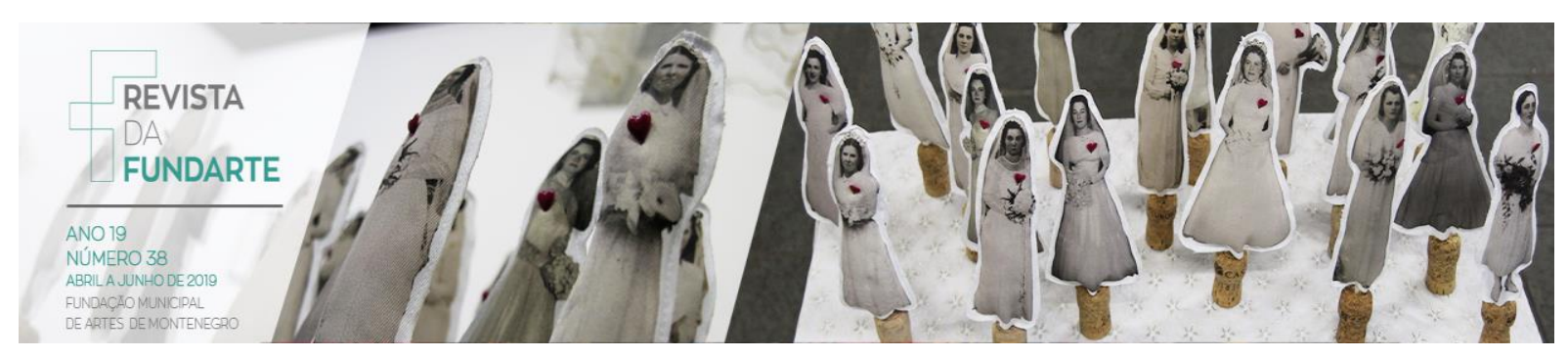

resolvida. Demoniza-se o erro esquecendo que ele é apenas uma tentativa de se chegar a um acerto. Castigar o erro é a castração das possibilidades de sucesso. Procurar não errar é uma censura no pensamento humano. E talvez o maior erro seja justamente essa procura "inchegável" do não errar, uma procura pela perfeição utópica e sempre distante da nossa realidade.

Se o erro faz parte da vida humana, naturalmente errar está imbuído em qualquer ação do homem. E o fazer artístico, uma ação tão antiga não está livre do erro. No entanto, diferente de alguns campos de estudo que trabalham com o descarte do errado, a prática artística consegue não apenas superar, mas também abarcar e utilizar o erro em seus produtos. Logo, o erro pode tornar-se uma ferramenta a ser considerada nesse fazer artístico ou até mesmo uma aliada nesse processo de expressão da arte.

Do ponto de vista da pesquisa em artes, o erro também merece consideração principalmente nas pesquisas que tenham como objetivo a produção de produtos artísticos, como bem colocam Romanini Junior e Bonfitto no artigo "A escrita dos erros", onde eles relatam experiências artísticas onde os desvios do objetivo, os erros, foram considerados e até incorporados. "Trata-se então de uma permissão ao registro das imperfeições, das arestas, das indecisões e hesitações, como indicadores de um processo vivo de investigação sensível. A constatação de um percurso vi(í)vido." (ROMANINI JUNIOR \& BONFITTO, 2015, p. 112).

Afinal, um processo artístico é uma longa estrada que muitas vezes não tem sinalização ou mesmo marcação do trajeto. O clima pode ser hostil e para prosseguir muitas vezes é preciso parar, voltar ou até reconfigurar a rota; em alguns momentos perder-se e às vezes acha-se; então como não considerar esses deslizes e desvios? Toda experiência afeta o artista de algum modo, de forma que é impossível desassociar o produto do caminho que foi passado. Uma solução viável é colocada: cabe ao artista inventar seu próprio modo de criar. Ou seja, é preciso que o artista-pesquisador tenha autonomia e ciência de suas escolhas e suas

ALMEIDA, Railson Gomes. A pesquisa participante e o erro na encenação de agreste (Malva-Rosa). Revista da FUNDARTE, Montenegro, p.79-94, ano 19, no 38, abril/junho de 2019. Disponível em: http://.seer.fundarte.rs.gov.br/index.php/RevistadaFundarte/index> 28 de junho de 2019. 


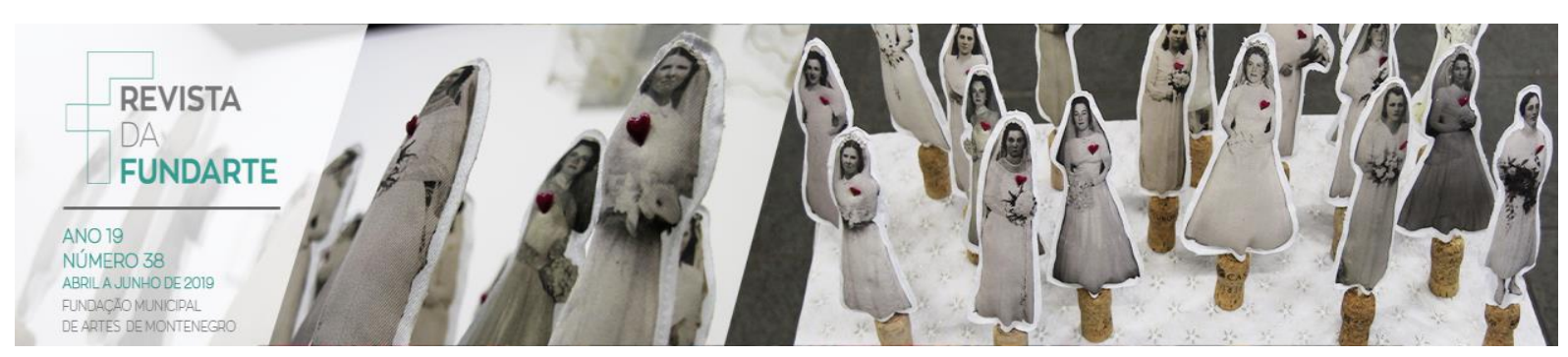

implicações. (PAREYSON, 1991, p. 59 apud ROMANINI JUNIOR \& BONFITTO, 2015, p. 113).

Opta-se por diferentes caminhos, "quebra-se a cara", coisas são jogadas fora, outras são guardadas. Durante esse percurso, um turbilhão de processamentos psicofísicos. Ao longo dos meses, a constatação de quantos inesperados surgiram e somaram-se à criação e de como estes atravessamentos foram benéficos ao processo, mesmo que ao final não tenham sido incorporados à cena. Mas a permissão do pesquisador ao inesperado, a retirada do próprio tapete, já é indicativo de um processo livre de paralisia, um cultivo do desconforto. Abrir espaço para a manifestação do inusitado soa, então, como um ato de coragem do pesquisador. (ROMANINI JUNIOR \& BONFITTO, 2015, p. 114).

É preciso assim, entender as pesquisas e processos artísticos numa perspectiva do "(Re)fazendo-se" como coloca Romanini Junior e Bonfitto, estando aberto a outros rumos, aos desvios, acidentes de trajetos, diferentes e inimagináveis lugares que o produto pode acessar. Errar é tentar. "O erro no processo de instauração da obra, não é engano: é aproximação. Errar é a dissipação das possibilidades da obra, apontando caminhos para aquela, ou talvez, para outras obras que virão." (REY10, 2002, p.129 apud ROMANINI JUNIOR \& BONFITTO, 2015, p. 116). Logo, é preciso tentar até encontrar o acerto ou considerar o erro como o próprio caminho desse acertamento.

\section{AGRESTE (MALVA-ROSA): “PARTICIPATIVIDADE” E ERRO}

Qual será a "verdade" na interpretação de uma experiência? [...] O mais importante, o decisivo é, depois que está tudo registrado e reconstruído, saber o que fazemos com isso. Temos de entender, compreender, interpretar a fundo o que ocorreu, quais foram suas causas, quais as consequências, quais os efeitos secundários e as raízes desses fenômenos. Devemos também interpretar quais têm sido as contradições, as continuidades e as descontinuidades, as coerências e as incoerências. (HOLLIDAY. In: BRANDÃO \& STRECK, 2006, Pag. 231; 230).

\footnotetext{
9 Trata-se da seguinte referência: PAREYSON, Luigi. Estética, teoria da formatividade. Petrópolis: Vozes, 1991.

10 Trata-se da seguinte referência: REY, Sandra. Por uma abordagem metodológica da pesquisa em artes. In BRITES, Blanca; TESSLER, Elida (Org.) O meio como ponto zero : metodologia da pesquisa em artes plásticas. Porto Alegre: E. Universidade/UFRGS, 2002.
}

ALMEIDA, Railson Gomes. A pesquisa participante e o erro na encenação de agreste (Malva-Rosa). Revista da FUNDARTE, Montenegro, p.79-94, ano 19, oㅡ 38, abril/junho de 2019. Disponível em: http://.seer.fundarte.rs.gov.br/index.php/RevistadaFundarte/index> 28 de junho de 2019. 


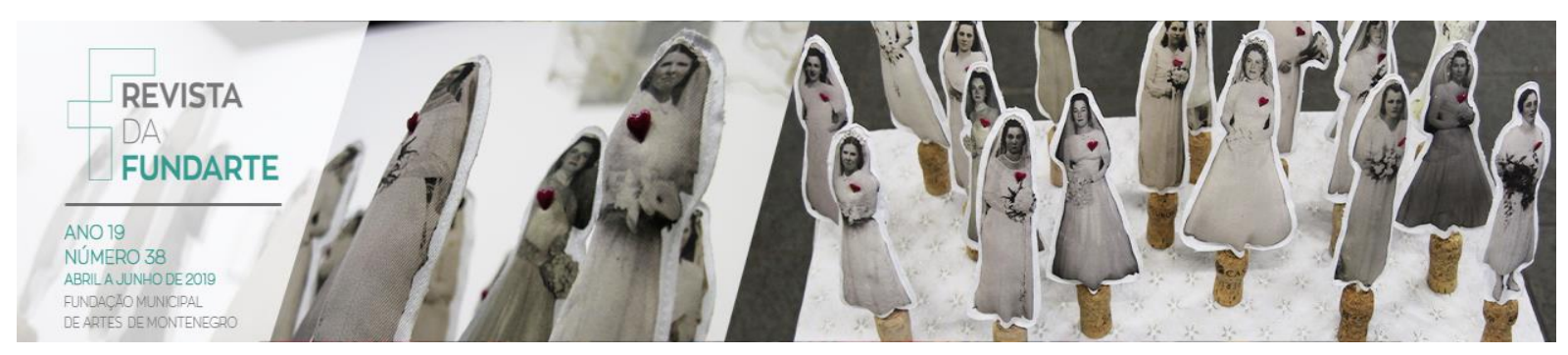

Como colocado anteriormente, a pesquisa participante prevê a ida do pesquisador a um determinado lugar em busca de uma melhor relação com 0 espaço e temática. Um processo parecido ocorreu no meio do processo de Agreste. No mês de abril o grupo inteiro viaja para a cidade de Boa Vista - PB, a cerca de $180 \mathrm{~km}$ da capital paraibana. O município encontra-se na região Cariri, tendo como bioma a caatinga ${ }^{11}$, cenário que remete ao citado no texto de Newton Moreno. Assim, o coletivo consegue "ter uma compreensão mais profunda da experiência com o fim de melhorar [...] a prática", nesse caso, da atuação no teatro. (HOLLIDAY. In: BRANDÃO \& STRECK, 2006, Pag. 232).

$\mathrm{Na}$ cidade de Boa Vista, o grupo foi à zona rural fazendo então uma visita ao Sítio Bravo, a $12 \mathrm{~km}$ do centro do município, fazendo então uma trilha em meio à caatinga $\mathrm{O}$ grupo observou a fauna e flora, tentando compreender a forma como ela se relaciona com o espaço e o clima da região. Observou também os moradores, sua forma de falar, andar e se comportar. Após a exploração no ambiente, o grupo procura alimentar-se de iguarias típicas da região, procurando vivenciar e se aproximar daquele contexto especifico. Assim, o coletivo que já havia estudo a dramaturgia, viaja em busca de elementos que venham a compor o espetáculo, para poder oferecer uma experiência mais próxima do real na encenação.

Após a viagem, os atores afetados com a observação propuseram algumas cenas que remetem diretamente ao espaço visitado, cenas que foram inseridas e absorvidas na encenação; cito algumas das novas proposições dos atores: $O$ ator Jofran Di Carvalho procura estabelecer uma corporeidade e composição vocal próxima a do bode, um animal típico da região por sua capacidade de resistir a longos períodos de seca. $O$ ator Railson Almeida passa a utilizar de um cajado encontrado no espaço remetendo aos idosos da região e procura um corpo com traços do galo, outro animal comum em regiões de estiagem. Os atores João Fernandes e Maria Bethânia inspiram-se nas pessoas mais velhas da região

\footnotetext{
11 "Caatinga é um tipo de vegetação formada de árvores de pequeno porte, arbustos tortuosos e plantas cactáceas. De modo geral, quase todas as plantas da caatinga possuem espinhos. É uma vegetação tipicamente brasileira, não existe em nenhum outro local".

FONTE: < https://www.significados.com.br/caatinga/> Acesso em: 26 jun 2018 às 14:00
}

ALMEIDA, Railson Gomes. A pesquisa participante e o erro na encenação de agreste (Malva-Rosa). Revista da FUNDARTE, Montenegro, p.79-94, ano 19, no 38, abril/junho de 2019. Disponível em: http://.seer.fundarte.rs.gov.br/index.php/RevistadaFundarte/index> 28 de junho de 2019. 


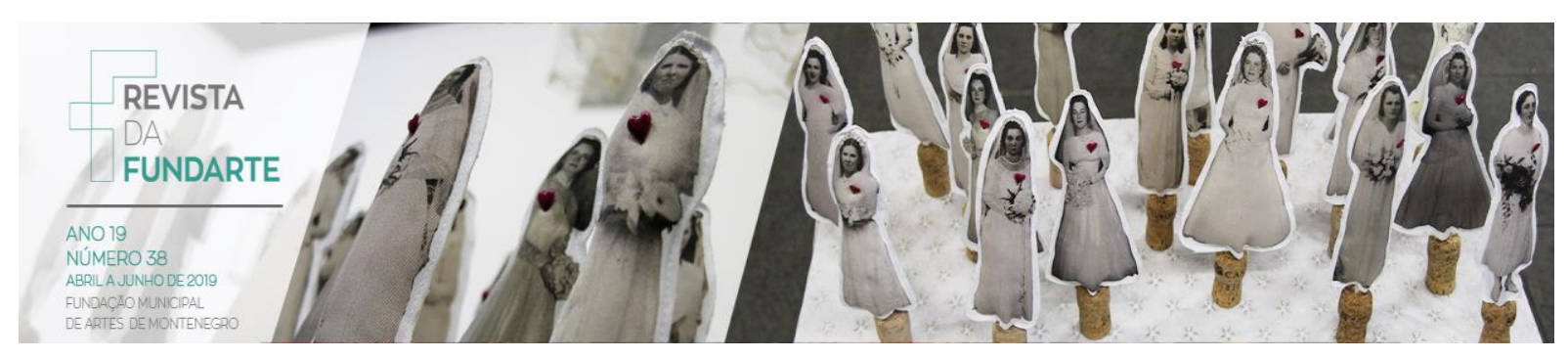

contando histórias, numa cena que tem essa característica de relato de história. $\mathrm{O}$ diretor Everaldo Vasconcelos, que também assina a sonoplastia do espetáculo, busca inserir ruídos e músicas que remetem ao que foi ouvido e vivenciado.

Todas essas mudanças citadas acabaram sendo incrementadas, no entanto, nada se deu de modo automático ou direto. Desde o inicio do processo, tudo foi um minucioso e continuo misto de repetição e novidades, até que o texto fosse, não apenas decorado, mas encarnado, de modo que os atores sabiam os textos um do outro e se ajudavam quando algum trecho era esquecido ou quando algum membro faltasse ao ensaio.

Procurando refletir sobre o papel da ideia de erro dentro do processo, é possível observar que dentro dele houve uma grande e rica relativização dos erros, ou seja, desvios do padrão esperado que ocorriam, mas que naturalmente se resolvia sem que fosse preciso o retardamento do processo. Então, por exemplo, quando no começo dos ensaios o texto não estava bem decorado, geravam-se algumas longas pausas em virtude do esquecimento das falas, porém muitas dessas pausas foram inseridas dentro da partitura vocal dos atores. Essas pausas deixam de ser lapsos da memória transformando-se em silêncios conscientes.

Outros "erros" também percebidos foram as entradas e saídas dos atores da cena para fora dela. Quando, no inicio, as marcações cênicas não estavam bem definidas era comum que algum ator adentrasse na cena errada. Isso também virou marcação no espetáculo final. O uso errado do figurino ou a falta dele também foram incluídos.

Outra variável, era a cenografia do espetáculo, que se tratava de objetos doados e achados, os quais eram ressignificados para compor as cenas. Isso obrigou os atores e a direção a encontrar modos cabíveis de inserção desses elementos. Houve ainda a adaptação da sala em si que se transformou em palco do espetáculo, gerando nos atores a necessidade de alterar corpo e voz ao público reduzido e próximo do palco.

Todos esses desvios poderiam ter sido considerados como erros, no entanto foram utilizados pelo coletivo como gatilhos para o crescimento do espetáculo. Os

ALMEIDA, Railson Gomes. A pesquisa participante e o erro na encenação de agreste (Malva-Rosa). Revista da FUNDARTE, Montenegro, p.79-94, ano 19, ํo 38, abril/junho de 2019. Disponível em: http://.seer.fundarte.rs.gov.br/index.php/RevistadaFundarte/index> 28 de junho de 2019. 


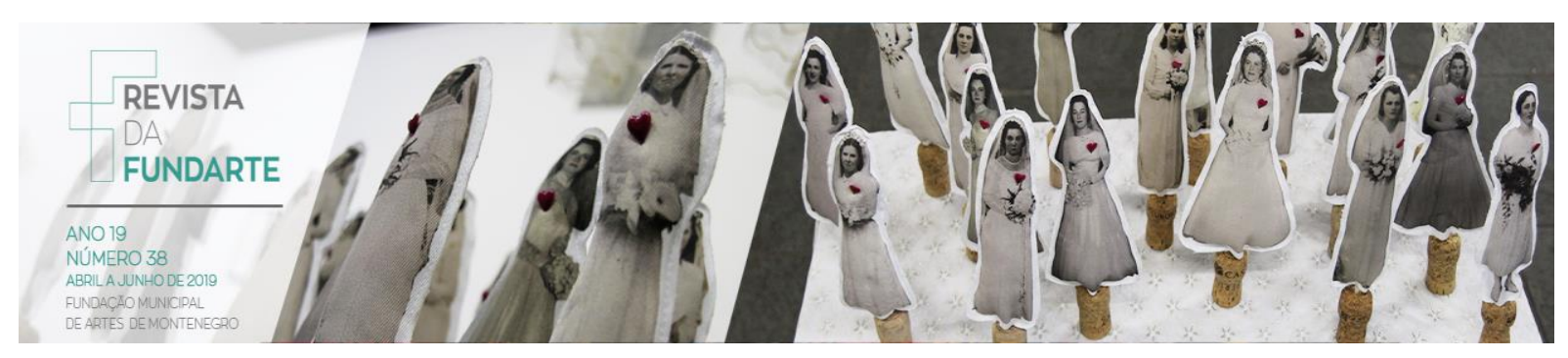

atores improvisaram mais e o diretor tornou-se mais aberto à sugestões para as mudanças de última hora. Foi nítido que a pesquisa no solo do cariri paraibano também abalou o processo, no entanto tratou-se de um abalo positivo, gerando modificações, abandono e criação de cenas. Enfim, todos esses "erros" só vieram a causar instabilidade, as quais potencializaram a encenação.

\section{CONSIDERAÇÕES FINAIS}

O dia amanhecia e as fagulhas resistiram queimando por dias. Cinzas. Silêncio. As fagulhas, em suspenso, como um eco, pairavam, sobre lavouras, varais e gerações.

[...]

Cruel, a natureza é

Dá o sol na desmedida

Dá um corpo na desmedida

Dá o amor na desmedida.

(MORENO, 2004, p. 104).

Refletindo acerca da pesquisa participante dentro da encenação é possível se aproximar da fala de Brandão e Streck (In: BRANDÃO \& STRECK, 2006, Pag. 9) "o pressuposto [...] do processo de conhecer o mundo anda de mãos dadas com sua transformação"; na qual se conclui que o ato transformador na encenação acabou sendo a viagem de campo, ou melhor, a pesquisa participante. Esse ideal converge também com a ideia de laboratório cênico, que é um procedimento onde os atores devem passar certo período de tempo inserido na realidade que ele vivenciará em breve, seja no teatro, na televisão ou no cinema. Isso torna a construção da personagem mais detalhada e verossímil para a observação do ouvinte. Dentro do espetáculo, por mais que se tivesse em mente os ideais realistas, a aproximação com a realidade de agreste auxiliou na construção dos corpos e das vozes, sendo possível perceber esses elementos no espetáculo final.

Acerca do erro, como colocado anteriormente, ele é apenas um elemento mal resolvido por algumas pessoas, como foi visto no texto do Romanini Junior e Bonfitto ele pode ser incorporado e potencializar seja uma escrita ou uma encenação como

ALMEIDA, Railson Gomes. A pesquisa participante e o erro na encenação de agreste (Malva-Rosa). Revista da FUNDARTE, Montenegro, p.79-94, ano 19, no 38, abril/junho de 2019. Disponível em: http://.seer.fundarte.rs.gov.br/index.php/RevistadaFundarte/index> 28 de junho de 2019. 


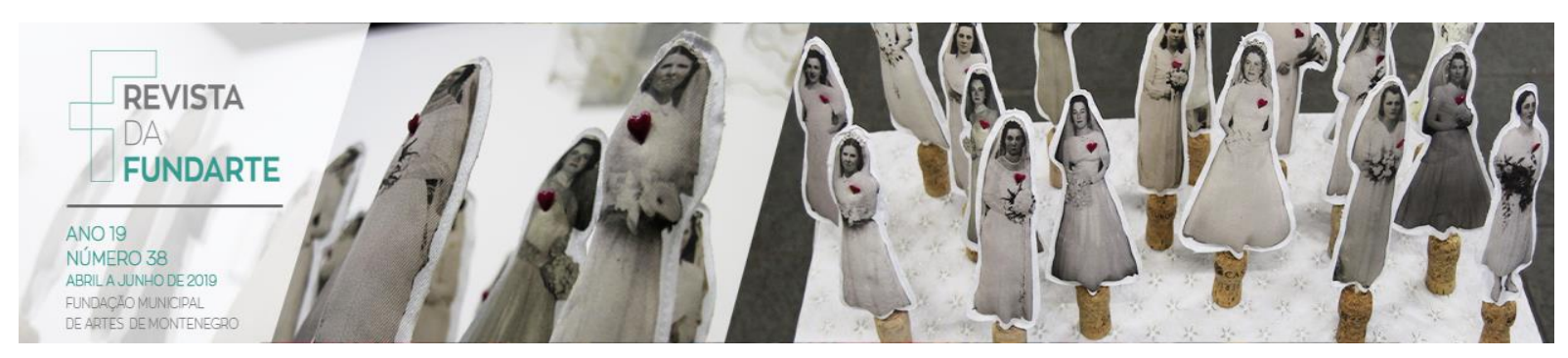

foi o caso de Agreste (Malva-Rosa). Os desvios do padrão que se ocorreram geraram potencialidades na encenação. Logo, é possível concluir que o espetáculo é repleto de "erros" que se tornaram "não-erros"; tudo isso graças ao desapego dos atores em relação a abandonar cenas já prontas e aceitar o desafio de estabelecer outras cenas; graças também a abertura da direção em acatar essas sugestões, não apenas dos atores, mas também do público que aparecia nos ensaios.

"É como dizia alguém, fazer uma parada no caminho para ver por onde temos caminhado e por que temos tomado o caminho." (HOLLIDAY. In: BRANDÃO \& STRECK, 2006, Pag. 235). Essa imagem consegue metaforizar o processo de encenação, um processo feito por um coletivo, em colaboração mútua que tem no seu corpo uma série de elementos e como frisado nessa pesquisa: Agreste (MalvaRosa) tem em seu processo uma pesquisa participante e a utilização dos desvios em sua encenação.

\section{Referências:}

BRANDÃO, Carlos Rodrigues; STRECK, Danilo Romeu. A pesquisa participante e a partilha do saber: uma introdução. IN: BRANDÃO, Carlos Rodrigues; STRECK, Danilo Romeu (Org.). Pesquisa Participante: O saber da partilha. $2 \stackrel{ }{ } \stackrel{ }{ }$ Ed. AparecidaSP: Ideias \& letras, 2006. p. $7-20$.

FERREIRA, Aurélio Buarque de Holanda. Mini Aurélio: o dicionário da língua portuguesa. 8르. Ed. Curitiba - PR: Positivo, 2010.

GABARRÓN, Luis R.; LANDA, Libertad Hernandez. O que é pesquisa participante? IN: BRANDÃO, Carlos Rodrigues; STRECK, Danilo Romeu (Org.).

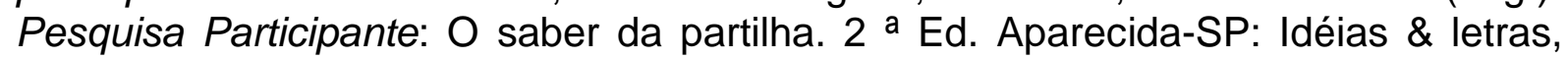
2006. p. $93-121$.

HOLLIDAY, Oscar Jara. Sistematização das experiências: algumas apreciações. Trad. Sérgio Herbert. IN: BRANDÃO, Carlos Rodrigues; STRECK, Danilo Romeu (Org.). Pesquisa Participante: $\mathrm{O}$ saber da partilha. $2 \stackrel{ }{ }{ }^{a}$ Ed. Aparecida-SP: Idéias \& letras, 2006. p. $227-243$.

MENEZES, Deborah Christina da Cruz. Agreste (Malva-Rosa): A ética em questão e a questão da ética na sala de ensaio. Trabalho de Conclusão de Curso. Bacharelado em Teatro, Universidade Federal da Paraíba. João Pessoa, 2017.

ALMEIDA, Railson Gomes. A pesquisa participante e o erro na encenação de agreste (Malva-Rosa). Revista da FUNDARTE, Montenegro, p.79-94, ano 19, no 38, abril/junho de 2019. Disponível em: http://.seer.fundarte.rs.gov.br/index.php/RevistadaFundarte/index> 28 de junho de 2019. 


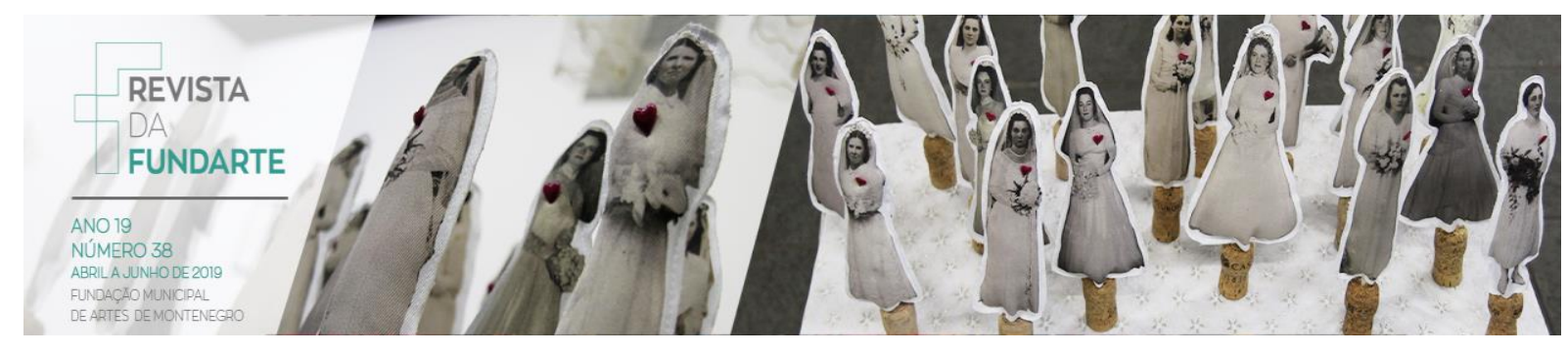

MORENO, Newton. Agreste (Malva-Rosa). IN: Revista Sala Preta, São Paulo - SP: Universidade de São Paulo, 2004, v. 4, p. 97 - 104.

ROMANINI JUNIOR, Moacir; BONFITTO, Matteo. A "escrita dos erros": sobre os possíveis modos de registro na pesquisa em artes da cena. IN: Revista Lamparina, Belo Horizonte - MG: Universidade Federal de Minas Gerais, 2015, v.2, n. 7, p. 111118.

ALMEIDA, Railson Gomes. A pesquisa participante e o erro na encenação de agreste (Malva-Rosa). Revista da FUNDARTE, Montenegro, p.79-94, ano 19, no 38, abril/junho de 2019. Disponível em: http://.seer.fundarte.rs.gov.br/index.php/RevistadaFundarte/index> 28 de junho de 2019. 